\title{
Applying to Graduate School in Engineering: A Practical Guide
}

\section{Dr. Katy Luchini-Colbry, Michigan State University}

Katy Luchini-Colbry is the Director for Graduate Initiatives at the College of Engineering at Michigan State University, where she completed degrees in political theory and computer science. A recipient of a NSF Graduate Research Fellowship, she earned Ph.D. and M.S.E. in computer science and engineering from the University of Michigan. She has published more than two dozen peer-reviewed works related to her interests in educational technology and enhancing undergraduate education through handson learning. Luchini-Colbry is also the Director of the Engineering Futures Program of Tau Beta Pi, the Engineering Honor Society, which provides interactive seminars on interpersonal communications and problem solving skills for engineering students across the U.S. 


\title{
Applying to Graduate School in Engineering: A Practical Guide
}

\begin{abstract}
This paper is a practical guide for applicants who wish to gain admission to graduate programs (Master's or PhD) in engineering in the United States. It discusses the typical timeline and key components of the graduate school application process, and presents detailed suggestions for developing academic resumes for graduate school applications. The paper also discusses the most common types of statements requested as part of graduate school application processes (academic, personal, and combined) and offers specific suggestions for developing strong statements.
\end{abstract}

\section{Introduction}

There are hundreds of high-quality programs in the United States that offer Master's and/or PhD degrees in various areas of engineering discipline. The American Society of Engineering Education (ASEE) produces annual "Profiles" of engineering programs that provides detailed information on graduate admissions, program size, graduate student expenses, typical financial aid, and many other significant details that can help prospective students identify programs that fit their academic, research and professional goals [1]. US News \& World Reports also provides an annual ranking of the top engineering graduate programs in the United States [2].

While the information provided through online profiles and rankings can provide prospective students with a starting point, in order to develop a robust graduate school application is it important to tailor your materials to each individual program to which you apply. This paper summarizes some key information about the typical graduate school application process for engineering disciplines, and provides practical advice for developing strong graduate school application materials. Please be aware that every institution has different requirements and deadlines; the information provided here can serve as a general guideline, but successful applicants will carefully review the specific requirements of each program to which they apply.

\section{Overview of the "Typical" Application Process}

Most graduate programs in the United States are set up on an academic calendar year, which typically begins in late August or early September. Some graduate programs will only admit new students to start in this "fall" term, while others will admit most students in the fall and a smaller cohort in the January term. The "fall start" is assumed throughout this document, since that is the most common timeline; if you are applying to begin graduate school in a different term, you will need to adjust the timelines suggested here accordingly.

In ideal circumstances, you would begin the graduate school application process no later than the summer before your final year of undergraduate studies. During this summer (or earlier), you should complete the following tasks: 
- Identify potential schools, based on your research interests, family/personal needs, geographic preferences, and career/personal goals.

- Determine if you are required to complete any graduate school competency exams, such as the GRE [3]; if so, study for and complete these exams

- Determine if you are required to complete any language examinations, such as the TOEFL [4]; if so, study for and complete these exams

- Identify $3+$ references, at least two of who are faculty members who know you well.

- Determine application deadlines for schools where you are interested in applying.

- Draft application statement(s).

Most graduate programs in engineering expect that you will apply 9-12 months in advance of the semester in which you wish to begin graduate school. Thus, during the fall term of your final year of undergraduate studies, you should complete the following tasks:

- Narrow your list of places to apply; generally 3-8 completed applications is a good goal. Ideally, you will apply to a range of schools (size, location, ranking, etc.) where you can make a strong case that you are a good investment and "fit" for their program.

- Identify your backup plan - "safety" school, work, volunteering, travel, etc.

- Prioritize your applications by deadline or your interest, realizing that you may get tired or run out of time and not complete all of the applications on your initial list.

- Complete and submit your applications; have transcripts, recommendations and test scores sent to each school.

- Confirm with each school that they have received all of your application materials

After the applications have been submitted, it typically takes several weeks for faculty to review the files and begin making admissions decisions. During the winter/spring term of your senior year of undergraduate studies, you can expect the following to happen:

- Faculty typically review graduate applications in January and February; a few early admissions may be sent in February, with the bulk of admissions decisions made in March. Admissions and financial aid decisions are often made separately.

- Visit each campus you are considering, meet with faculty and current graduate students, tour the facilities, consider living options, etc.

- Decide on a graduate program, typically in April.

In the United States, the Council of Graduate Schools has established an "April 15 Resolution" [5] that governs how many graduate programs make offers of financial support to prospective graduate students. This Resolution has two key tenets: first is the idea that an offer of financial support from an institution to a graduate student constitutes an agreement between both parties, and once accepted that offer should be honored. The second key idea is that prospective graduate students have until April $15^{\text {th }}$ to make a final decision about accepting an offer of admission with financial support from a graduate program. Before April $15^{\text {th }}$, prospective students are free to change their minds; after April $15^{\text {th }}$, an accepted offer of financial support is considered binding and students are not free to accept offers from other institutions without first 
obtaining written permission from the original institution, releasing the student from the original agreement.

\section{Academic Resumes}

Many graduate programs request that you submit a resume with your application materials. You should tailor this resume to graduate school, and follow any specific content or layout requirements indicated by the graduate program. The following bullets cover some of the typical components of an academic resume, but please realize that not all of these may apply to you.

- Contact information: make sure that your name is highly visible and that there is clear contact information, including a professional email address and a phone number. It is not always necessary to include multiple phone numbers or addresses; consider how else you might be able to use that space.

- Objective: on an academic resume, this is typically not necessary since you will explain your objectives for pursuing a graduate degree in detail in your application statement(s).

- Education: include your college degree information, expected graduation term, and GPA with scale (e.g., 3.358/4.0). As appropriate, include additional majors/minors, concentrations, study abroad activities, or accomplishments (Dean's List, Honors College membership, etc.). Also list professional training activities or certifications (e.g., EIT or PE status; certification in software or equipment), training completed as part of a co-op or internship, and other professional development activities you have participated in (teamwork training, communications skills seminar, etc.).

- Research Experience: include both paid and volunteer experiences, as well as substantial research projects completed as part of your technical coursework. Use a descriptive position title ("Undergraduate Research Assistant", "Team Leader, Senior Design Project") and include the name of the course or the lab/faculty member you worked with. Use bullets to describe the research skills you developed, specialized software or equipment you used, and how your work contributed to a larger research project. If your project was funded externally, indicate the funding source (NSF, NIH, DOD, etc.).

- Professional Experience: include both paid and volunteer opportunities in engineering or other technical fields. Use a descriptive position title ("Engineering Co-Op", "Software Development Intern") and include the name of the company or organization. Use bullets to describe the technical, engineering or research skills you developed, specialized software or equipment you used, and how your work contributed to a larger effort within the organization.

- Research and Professional Experience: depending on your background, it may be appropriate to combine the previous two headings into one.

- Teaching Experience: if you have substantial experience teaching or assisting in an academic setting (as an undergraduate teaching assistant, a tutor, etc.) you should include that somewhere in your academic resume. If you do not have enough teaching experience to justify a separate section, you should include it with your professional experience.

- Publications and Presentations: common types include journal papers, conference proceedings/presentations, workshops, and posters; if you have substantial publications you may want to separate this section into more than one header. Include posters 
presented at undergraduate research forums; presentations made as part of co-op experiences or internships; and technical papers that have been accepted, submitted or are in preparation. Indicate co-authors as appropriate.

- Skills: if you are applying to a graduate program where specialized skills would be desirable, it might be appropriate to list them in a separate section. Examples might include experience with laboratory equipment, testing techniques, or software tools. Remember that it may be more appropriate to integrate these skills into your research or professional experience section - it will depend on the extent of your experiences.

- Outreach and Service: emphasize STEM (science, technology, engineering, math) outreach programs or activities you have participated in, describing the audience (e.g,. K12 students, high school teachers) and activity. Include other leadership and volunteer activities on campus and in the community.

- Honors and Awards: list scholarships, honors and awards that you have received. If you need to save space, consider a brief description of related awards (e.g., "College and Departmental Scholarships for Academic Achievement, awarded 2012-16") rather than an exhaustive list. Emphasize honors related to your research or engineering experiences, such as best paper/poster awards, academic achievements, etc.

- Formatting: Use a standard font style that is very easy to read - something like Times New Roman, Verdana, Arial, etc. Make sure that the font size is also readable (usually $10+$ point). Avoid using italics or underlining. Use CAPS or bold to emphasize information. Leave some whitespace on the page; one-inch margins on all sides are typical. Many career service professionals suggest that you NOT use an existing Microsoft Office (or similar) resume template, as that suggests that you lack the word processing skills to format a document on your own and may limit the information you can include.

Most undergraduates have enough experience by graduation for a one-page resume. Longer resumes might be appropriate if you have extensive undergraduate experiences. In general, you should not include experiences prior to college or non-engineering/research/technical experiences. An exception would be if you had a substantial engineering or professional experience in high school (an internship, leadership in a STEM outreach program like FIRST Robotics, research experience, etc.).

\section{Academic Statements}

Many institutions have specific criteria or guidelines for academic statements; other institutions will simply ask for an academic statement and you will have to develop your own format. If you are not given specific prompts, your Academic Statement should be a concise description of your plans for graduate study, your career goals, and how the specific graduate program to which you are applying will help you meet your career and educational objectives. If you have already been in contact with faculty or staff at the institution to which you are applying, you should list those contacts in your Academic Statement (unless the school asks for them in a separate part of the application).

When preparing a general Academic Statement, you should briefly describe key experiences that led you to graduate studies. Examples might include research experiences, internships, 
coursework or extracurricular activities. Share specific, relevant examples of how these experiences helped you develop skills for success as a graduate student. For instance, you might demonstrate ways that you have synthesized knowledge from the classroom, developed research skills, communicated effectively, acted as a leader, or gained skills and responsibility over time. Make a clear connection between your previous experiences and your current interest in graduate studies. If your intended area of specialization in graduate school differs significantly from your previous experiences, explain briefly why you decided to change focus. If applicable, explain any gaps or discrepancies in your academic record and share unusual obstacles or hardships that you have overcome in pursuit of your educational objectives. Explain how your goals for graduate study relate to your longer-term career plans, including the pursuit of additional degrees or certifications if applicable.

\section{Personal Statements}

Many institutions have specific criteria or guidelines for personal statements; other institutions will simply ask for a personal statement and you will have to develop your own format. Typically, a Personal Statement should concisely describe how your background and life experiences - including social, economic, cultural, familial, educational, or other opportunities or challenges - motivated your decision to pursue a graduate degree. When preparing a general Personal Statement, you may find it helpful to address some or all of the following questions:

- How well do your personal goals for education and research fit with the interests of the faculty and the research activities within the department or program to which you are applying? Briefly describe research areas or questions that you find interesting and identify any specific faculty, labs or research projects at the institution that are of particular interest to you.

- How have you demonstrated your leadership skills, or your potential as a leader? For example, you might share specific examples of how you made contributions as an officer in a student organization or how you assumed a leadership role within a team or during a professional internship. You could also discuss your potential for leadership in graduate school and afterwards by sharing your career goals and discussing your capacity to make a distinctive professional or scholarly contribution in your field.

- How have you contributed to a diverse educational community, or how will you do so as a graduate student? How have you promoted understanding among persons of different backgrounds and ideas, or how will you do so as a graduate student? Examples might include service activities, leadership roles, study abroad, language study, etc.

- If applicable, describe any barriers or obstacles that you have overcome in pursuit of your educational or personal goals. Examples might include economic, social or health challenges, being the first in your family to attend college, family obligations, etc.

- If applicable, describe aspects of your personal background that will enhance the diversity of the institution's graduate student body, such as being multi-lingual, participating in a McNair or TRIO program, attending a minority-serving institution, etc.

- If applicable, describe anything else in your personal history, experience, or aspirations that distinguishes you from other applicants to this graduate program.

If you choose to disclose personal challenges or obstacles that you have overcome, be certain to 
provide only as much information as you are comfortable having potential faculty mentors and colleagues know - while application materials are part of your private record, they are read by faculty within the department or programs to which you apply. Alternatively, if you have not experienced any unusual obstacles or challenges in your education or personal history, simply skip over those questions in the application materials.

\section{“Combined" Application Statements}

Some institutions ask for a single application statement, which may combine elements of "typical" academic and personal statements. If the institution you are applying to does not have specific criteria or guidelines for your application statement, you may find the following general outline helpful in drafting a single / combined application statement.

- Introduction: what makes you unique? Start an interesting story that engages the reader.

- Experiences that led you to graduate school: continue the story by sharing specific, relevant experiences that helped you develop skills for success as a graduate student. Demonstrate ways that you have synthesized knowledge from the classroom, developed research skills, communicated effectively, and acted as a leader. Show that you have gained skills and responsibility over time. If applicable, explain any gaps or discrepancies in your academic record and share unusual obstacles or hardships that you have overcome.

- Reasons for graduate study: make a clear connection between your previous experiences and your current desire to go to graduate school. Describe the research areas and questions that interest you, and identify 2-3 faculty members or research labs/projects of interest at the specific school. Describe how your background and experiences have prepared you to do research in that area, and if necessary explain your decision to pursue research that differs significantly from your previous experience.

- Conclusion: Share how your goals for graduate study relate to your longer-term career plans, including pursuit of additional degrees if applicable. Express enthusiasm for graduate study and highlight aspects of this school's graduate program that will allow you to gain the experience and skills that you desire.

\section{Additional Resources}

As you develop your graduate school application materials, be sure to request feedback from your faculty mentors, the Writing Center or English-language help center on your college campus, or a local career counselor or academic advisor. You should also carefully review the websites of the graduate departments/programs to which you are applying, to determine if there are specific requirements or instructions for applications to their institution.

The Committee on Institutional Cooperation (CIC) offers a general resource for those considering graduate studies in any area called "Applying to Graduate School: Tips, Timeline, and Tools of the Trade" [6]. There are numerous online resources to assist you in developing robust application materials for graduate school as well. For example, the Purdue OWL (Online Writing Lab) offers a variety of information about resumes and vitas, including samples [7]. The Resume Resource has some examples of CVs (aka "academic resumes") that you may find 
interesting [8]. Purdue's OWL has also compiled resources for developing statements for graduate school applications, including example statements, advice from admissions officers, and top 10 lists of things to do (or not to do) in your application [9]. Peterson's EssayEdge offers multiple "lessons" on how to write graduate application statements, including structure, style, and tone, as well as many sample essays and concrete "before" and "after" examples [10].

\section{References}

[1] “ASEE.org - ASEE - Publications - College Profiles - Search the Profiles." [Online]. Available: http://profiles.asee.org/. [Accessed: 16-Apr-2014].

[2] "Best Graduate Schools | Top Graduate Programs | US News Education - US News." [Online]. Available: https://usnews.com/best-graduate-schools. [Accessed: 28-Mar-2017].

[3] "The GRE Tests." [Online]. Available: https://www.ets.org/gre/. [Accessed: 28-Mar-2017].

[4] “The TOEFL ${ }^{\circledR}$ Test," The TOEFL ${ }^{\circledR}$ Test. [Online]. Available: https://www.toeflgoanywhere.org/front. [Accessed: 28-Mar-2017].

[5] "April 15 Resolution | Council of Graduate Schools." [Online]. Available: http://cgsnet.org/april-15-resolution. [Accessed: 28-Mar-2017].

[6] "CIC_GradSchoolGuide.pdf.".

[7] "The Purdue OWL: Résumés and Vitas." [Online]. Available: https://owl.english.purdue.edu/owl/section/6/23/. [Accessed: 28-Mar-2017].

[8] "Curriculum Vitae CV Examples," Resume and Cover Letter Examples and Writing Guides, 20-Feb-2012. [Online]. Available: http://www.resume-resource.com/curriculumvitae-cv-examples/. [Accessed: 28-Mar-2017].

[9] "Purdue OWL: Writing the Personal Statement." [Online]. Available: https://owl.english.purdue.edu/owl/resource/642/01/. [Accessed: 28-Mar-2017].

[10] "Detailed Instruction to Write a Graduate School Personal Statement - EssayEdge." [Online]. Available: https://www.essayedge.com/graduate/essayadvice/course/. [Accessed: 28-Mar-2017]. 